\title{
Rewiring the Addicted Brain: Circuits-Based Treatment for Addiction
}

\author{
Graziella Madeo ${ }^{1,2}$ and Antonello Bonci ${ }^{2,3,4}$ \\ ${ }^{1}$ Novella Fronda Foundation, Human Science and Brain Research Piazza Castello, \\ 16-35141 Padua, Italy \\ ${ }^{2}$ Intramural Research Program, National Institute on Drug Abuse, National Institutes \\ of Health, Baltimore, Maryland 21224, USA \\ ${ }^{3}$ Solomon H. Snyder Department of Neuroscience, Johns Hopkins University School of Medicine, \\ Baltimore, Maryland 21287, USA \\ ${ }^{4}$ Department of Psychiatry and Behavioral Sciences, Johns Hopkins University School of Medicine, \\ Baltimore, Maryland 21287, USA \\ Correspondence: antonello.bonci@nih.gov
}

\begin{abstract}
The advent of the noninvasive brain stimulation (NIBS) technique has paved the way for neural circuit-based treatments for addiction. Recently, evidence from both preclinical and clinical studies has evaluated the use of transcranial magnetic stimulation (TMS) as a safe and cost-effective therapeutic tool for substance use disorders (SUDs). Indeed, repetitive TMS impacts on neural activity inducing short- and long-term effects involving neuroplasticity mechanisms locally within the target area of stimulation and the network level throughout the brain. Here, we provide an integrated view of evidence highlighting the mechanisms of TMS-induced effects on modulating the maladaptive brain circuitry of addiction. We then review the preclinical and clinical findings suggesting rTMS as an effective interventional tool for the treatment of SUDs.
\end{abstract}

Drug addiction is a chronic relapsing brain disorder, characterized by compulsion to seek and take the drug, loss of control in limiting the intake despite harmful consequences, and negative emotional state when access to the drug is prevented (American Psychiatric Association 2013). The term addictions is now encompassed by the term substance use disorders (SUDs), since the DSM-5 consider substance abuse and substance dependence as one diagnostic construct in which the severity of SUDs ranges from mild to moderate depending on how many criteria apply (American Psychiatric Association 2013). Compelling evidence has shown that the initial exposure to substance abuse exerts a reinforcing effect by activating reward circuits in the brain mainly encoding for a voluntary behavior, whereas the repeated drug administration progressively impairs brain functions by altering the ability to self-control over drug-seeking and -taking behaviors (Volkow et al. 2016). Classically, an SUD is conceptualized as a complex three-stage recurring cycle, worsening over time and involving neuroplastic changes in three major circuits: (i) reward-basal ganglia system in the binge/ intoxication stage; (ii) extended amygdala and stress response system dysfunctions related to the withdrawal negative affect stage; and (iii) prefrontal cortex (PFC) and executive function systems related to the preoccupation/ anticipation stage (Goldstein and Volkow 2002; George and Koob 2010). Progress in understanding the neurobiology of addiction has been made through the study of either animal models or brain-imaging studies in addicted indi- viduals (Kenny et al. 2018). Translating the preclinical findings into clinical applications to set an effective therapeutic intervention for addiction still presents a challenge. Cognitive behavioral therapy, motivational interviewing, contingency management, and spiritual engagement are used as preventive and treatment strategies to reduce substance use with modest and short-term effectiveness. A better understanding of the neurobiological mechanisms underlining SUDs has allowed us the development of pharmacological compounds based on the receptor system implicated. Ideally, the technological advances in drug development should enable the design of drugs that can specifically target the receptor subtypes involved in the pathophysiology of SUDs. However, the pharmacotherapy for SUDs is still very limited in terms of efficacy and tolerability. Indeed, despite the elegant and precise modulation of distinct neurotransmitter systems, these compounds are not able to limit their site of action to a specific brain area or circuit. The broad action of these compounds, strictly related to the likelihood of having side effects, is particularly evident when targeting the glutamatergic or GABAergic neurotransmitter system. As a result, whereas for some SUDs there are Food and Drug Administration (FDA)-approved medications (e.g., naltrexone and acamprosate for alcohol use disorder; naloxone for opiate use disorder), for others, like cocaine or methamphetamine, there are no FDA-approved interventions. Recently, there has been a growing interest designing neural circuit-based therapeutic interventions for individ-

(C) 2018 Madeo and Bonci. This article is distributed under the terms of the Creative Commons Attribution License, which permits unrestricted reuse and redistribution provided that the original author and source are credited. 
uals with SUDs. Findings from preclinical studies have shown a causal relationship between frontostriatal circuit activity and drug-related behaviors (Chen et al. 2013a; Stefanik et al. 2013). Moreover, clinical studies have shown that activity in the same frontostriatal circuits are useful as biomarkers for predicting vulnerability to relapse in several SUDs (Hong et al. 2009; Sinha 2011; Bunce et al. 2013). Thus, the hypothesis that applying brain stimulation to those circuits could potentially revert some of the drug-induced neuronal adaptations and reduce addictive behaviors has been investigated in both preclinical and pilot clinical studies. Basic science studies showed that the activation of infralimbic brain areas, such as the PFC, via either electrical or optogenetic stimulation, results in a reduction of drug intake in rats (Levy et al. 2007; Chen et al. 2013a). In humans, brain stimulation of targeted brain regions can be achieved noninvasively by using transcranial magnetic stimulation (TMS). TMS is a noninvasive brain stimulation technique that delivers fluctuating magnetic field pulses through the skull into the brain, where electrical currents are generated, and thus the neuronal activity modulated (Hallett 2000). Repetitive TMS (rTMS) pulses in sequences at specific parameters can induce long-term changes within the neuronal circuits and influence specific behaviors. In this report, we discuss the TMS-induced changes in neuroplasticity and connectivity, possibly underlining its long-term effects, as well as the advantages and drawbacks of this technique. We describe the preclinical findings obtained using optogenetics in rodents, demonstrating that the stimulation of prefrontal cortical circuits reverts the compulsive seeking of drugs. Then, we link these observations to those from imaging and neurophysiologic studies in humans where rTMS has been been shown to be effective in reducing drug craving and drug intake. Finally, we highlight the new advances and the conceptual gaps that need to be filled by future preclinical and clinical studies.

\section{NEUROBIOLOGY OF TRANSCRANIAL MAGNETIC STIMULATION (TMS)-INDUCED EFFECTS}

TMS is a noninvasive physical method based on the electromagnetic induction principle, in which fluctuating magnetic field pulses are delivered and, passing through the skull, reach the targeted brain areas (Hallett 2000). The magnetic field generates electric currents able to induce changes of neuronal excitability in the brain area where the coil is positioned over the scalp. TMS is a very flexible tool, as different stimulation parameters can induce distinct neuronal mechanisms. TMS pulses can be delivered as single pulse (spTMS), as a couple of pulses (paired-pulses, pp-TMS), or as a repetitive sequence of pulses at specific frequencies (rTMS) or patterned with a train of pulses sequence and a specific intertrain interval (theta-burst stimulation [TBS]) (Hallett 2000; Rossi et al. 2012). Depending on stimulation parameters, TMS can induce shortor long-term effects and modulate the neuronal activity by eliciting a facilitative or suppressive effect on cortical ex- citability. Although spTMS and ppTMS are mainly used to study timing-dependent neuronal processes lasting fraction of seconds (e.g., changes in the magnitude of motor evoked potentials [MEPs]), rTMS and TBS have been associated with long-lasting changes within neuronal circuits influencing behavioral responses and possibly offering a therapeutic option. These TMS-induced aftereffects are critically dependent on stimulation parameters, such as frequency and/or pattern of stimulation, stimulation intensity, and anatomical loci (Hallett 2000). In general, rTMS at low frequency $(\leq 1 \mathrm{~Hz})$ determines a suppressive effect on neuronal activity reducing cortical excitability, whereas higher frequencies $(5-25 \mathrm{~Hz})$ typically have a facilitatory effect, increasing neuronal activity and cortical excitability (Hallett, 2000; Diana et al. 2017). rTMS neuronal effects persist for at least several minutes and can influence behavioral response. The TMS behavioral effects can be partially state-dependent, meaning that the cortical activity before or during TMS may influence whether TMS facilitates or suppresses behavioral responses (Silvanto et al. 2008). In humans TMS effects on brain physiology can be studied in the primary motor cortex (M1) by recording the elicited MEPs from peripheral muscles and by using electroencephalography (EEG) and functional neuroimaging techniques (e.g., positron emission tomography, functional magnetic resonance) (Paus and Barrett 2004; Siebner et al. 2009; Ilmoniemi and Kičić 2010). Relevant additional information come from both in vitro (Edgley et al. 1997; Jackson et al. 2016) and in vivo (Cirillo et al. 2017) studies using computational modeling, pharmacological approaches, and circuit-specific modulation (Ilmoniemi et al. 1999; Cohen et al. 2004; Silva et al. 2008; Salvador et al. 2011). All together these studies have shown that TMS causes direct effects activating the targeted brain area under the coil and indirect effects of remote cortical and subcortical areas anatomically connected to the primary activation site (Ilmoniemi et al. 1997; Bestmann et al. 2004; Paus and Barrett 2004; Di Lazzaro et al. 2012).

\section{TMS Factors and Mechanisms for Neuroplasticity}

Animal, human neuroimaging, and elctromyographic (EMG) studies have provided considerable insights into the mechanistic bases of TMS. EMG studies in which spTMS was used to stimulate the motor cortex as a model region allowed the assessment of neuroplastic changes within corticospinal excitability. Delivering rTMS at high frequency $(5-25 \mathrm{~Hz})$ has a facilitatory effect on motor corticospinal excitability, whereas low-frequency inhibits cortical excitability. Similarly, intermittent TBS and continuous TBS can facilitate or suppress motor cortical excitability, respectively (Pascual-Leone et al. 1994). Both animal and human studies have shown that one of the hypothezised mechanisms underlying the long-term neuroplastic changes induced by TMS is an LTP- or LTD-like phenomenon at the synaptic level (Pell et al. 2011; Hanlon et al. 2015; Cirillo et al. 2017; Diana et al. 2017). The occurrence of LTP or LTD is dependent on the stimulation parameters, such as frequency, stimulation intensity and duration, anatomical loci, coil shape, and modulation of 
the glutamatergic postsynaptic signaling (Huang et al. 2005; Labruna et al. 2016; Cirillo et al. 2017). Although the detailed mechanisms are still poorly understood, there is a general agreement that high-frequency stimulation $(10-20 \mathrm{~Hz})$ rTMS or iTBS with a duration between 7 and 20 min over the motor cortex produces a rapid postsynaptic influx of calcium ions and a long-lasting increase in the amplitude of the MEP, suggesting there are LTP-like effects on cortical excitability (Pascual-Leone et al. 1994; Cárdenas-Morales et al. 2010). Conversely, low-frequency rTMS $(1 \mathrm{~Hz})$ or cTBS with a duration between 9 and 15 min elicits a decrease of MEP amplitude, inducing LTD-like effects (Pascual-Leone et al. 1994; CárdenasMorales et al. 2010). Although these observations could explain the differences between high- and low-frequency rTMS, or intermittent and continuous TBS, the underlying downstream mechanisms are more complex and still require further investigation (Tigaret et al. 2016). Duration, number of sessions, and number of pulses are also important factors for clinical TMS effects. Some studies focusing on patients with depression have shown that longer stimulation protocols (e.g., doubling the number of rTMS pulses or number of sessions) can induce better clinical effects (Hadley et al. 2011; Modirrousta et al. 2018; Schulze et al. 2018). Nevertheless, other studies suggest that longer duration or greater intensity does not necessarily increase the clinical efficacy. Indeed, facilitatory aftereffects are converted to suppressive when doubling the duration of iTBS or increasing the intensity (Gamboa et al. 2010; Doeltgen and Ridding 2011). Stimulation parameters are not only the important factors to determine the directionality of neuroplasticity changes. Several studies have shown how the baseline cortical activation state influences the stimulation aftereffects of TMS (Silvanto et al. 2008). From a homeostatic plasticity perspective, any external intervention preceding or following the stimulation can determine the direction of synaptic plasticity because of the regulatory mechanisms that allow the system to maintain an equilibrium condition (Silvanto et al. 2008; Karabanov et al. 2015; Cirillo et al. 2017). It is clear that a number of interacting mechanisms may underlie the variability of cortical excitability changes. Preclinical studies on cellular and animal models, even not reproducing the exact human brain condition, have provided relevant details regarding the TMS-induced effects at a cellular level. One of the proposed mechanisms involves the simultaneous activation of presynaptic and postsynaptic sites similar to classical NMDA receptor-dependent Hebbian plasticity (Vlachos et al. 2012; Lenz et al. 2015). Synaptic transmission changes are paralleled to morphological modification involving spine formation and pruning, as observed in entorhinal and hippocampal slice culture (Lenz et al. 2015). It is likely that multiple mechanisms at different levels play a role in rTMS plasticity; acute synaptic events can trigger long-term changes through dendritic spine remodeling and neurotransmitter signaling regulation (Chervyakov et al. 2015; Lanza et al. 2015; Lenz et al. 2015). Finally, nonsynaptic mechanisms may also add further complexity to this scenario. Indeed, activation of neurotrophic factor signaling (Zhang et al.
2007; Cheeran et al. 2008; Chervyakov et al. 2015), modulation of glial cells (Chen et al. 2013b; Chervyakov et al. 2015; Cirillo et al. 2017), and epigenetic modification (Etiévant et al. 2015) can play a role in determining the long-term aftereffects of rTMS.

\section{REWIRING BRAIN CIRCUITRY FOR SUDs}

Neurobiological studies of SUDs have clearly shown the relationship between the increase of neuronal activity within the meso-cortico-limbic system and the acute reinforcing and rewarding effects of stimulant drugs (Volkow et al. 1996; Everitt and Robbins 2005). As stimulant drug, cocaine induces a rapid increase of dopamine level within the meso-cortico-limbic circuit (Volkow et al. 1996) and changes in glutamatergic and GABAergic systems that critically intervene in sustaining addictive behaviors (Feltenstein and See 2009; Diana et al. 2017). The meso-cortico-limbic system includes dopamine projections from neurons in the ventral tegmental area (VTA) to nucleus accumbens (NAc), amygdala, hippocampus, and cortical areas, such as the PFC and the anterior cingulate cortex (ACC) (Goldstein and Volkow 2002; Diana et al. 2017). Chronic exposure to drugs, including cocaine, induces long-term neuroadaptations because of the repeated hyperactivity of dopaminergic transmission and results in alterations of cortical neurotransmission and excitability (Koob and Volkow 2010), involving frontocortical areas. Neuroimaging studies of addicted individuals showed alterations within key frontal brain regions (Goldstein and Volkow 2011), including the dorsolateral prefrontal cortex (DLPFC) that regulates goal-directed behavior, the orbitofrontal cortex (OFC) related to decision-making, impulsivity, and behavioral inhibition, and the ACC involved in error detection (Volkow et al. 2003; Jovanovski et al. 2005; Goldstein and Volkow 2011; McHugh et al. 2013). Abnormalities within the PFC-striato-thalamic circuits are believed to play a central role in compulsive drug-seeking behavior and relapse. Neuropsychological findings suggest that frontal circuitry dysfunction reduces the ability to inhibit behavioral responses in favor of drug-seeking. Targeting dysfunctions in the meso-cortico-limbic system may contribute to design effective therapeutic interventions for reverting addicted-related behaviors, such as craving, compulsive drug use, and relapse. Here, we describe findings coming from both preclinical and clinical studies supporting the therapeutic role of rTMS in treating cocaine addiction.

\section{Evidence from Preclinical Studies}

Preclinical models have certainly disentangled some of the cellular and molecular mechanisms by which TMS exerts neurophysiological effects potentially supporting the clinical improvements of addictive symptoms. Several animal studies have explored the possibility of using TMS or TMS-like protocols, targeting the frontal brain region, as a nonpharmacological intervention for addiction. 
Repeated brain stimulation of the PFC has been found to affect cocaine addiction-related behaviors in rodent models (Feil and Zangen 2010). These effects can be related to the increase of dopamine release in the NAc following rTMS protocols (Strafella et al. 2001; Kanno et al. 2003; Feltenstein and See 2009). Indeed, although drug consumption is associated with an increased level of dopamine within reward circuitry, dopaminergic activity is reduced during the withdrawal stage. This hypodopaminergic tone has been related to the occurrence of craving and relapse (Nestler 2005; Kalivas and O'Brien 2008). By using in vivo neurochemical techniques, such as microdialysis, it has been shown that acute rTMS over frontal brain regions significantly increased dopamine release in the dorsal hippocampus, dorsal striatum, and PFC (Kanno et al. 2003). Therefore, the increase in dopamine level induced by repeated brain stimulation can reduce craving in individuals under withdrawal conditions (Blum et al. 2008). Our understanding of the neural circuitry regulating drug-seeking and cue-induced reinstatement has significantly advanced via development in optogenetics (Diana et al. 2017). Using this technique, specific neuronal populations, infected with channelrhodopsin or halorhodopsin, can be selectively activated or inhibited through exposure to different light frequencies (Berndt and Deisseroth 2015). Thus, in vivo optogenetic stimulation of the PFC prevented the compulsive seeking behavior in rodent models of cocaine selfadministration, whereas inhibition of the same region led to an increase in cocaine-seeking (Chen et al. 2013a; Stefanik et al. 2013; Diana et al. 2017). Despite the limitations of animal studies, these findings provide the neurobiological basis for a therapeutic role of rTMS-driven PFC stimulation in treating cocaine addiction (Levy et al. 2007; Amiaz et al. 2009; Diana et al. 2017).

\section{Evidence from Human Studies}

The long-lasting modulatory effects of TMS have been shown to be promising as therapeutic interventions for a large variety of neurological and psychiatric disorders. DLPFC has been selected as the stimulation target in most addiction studies so far. Specifically, rTMS evaluating its therapeutic use in addiction has targeted most often the left DLPFC with excitatory stimulation. The large majority of these studies have evaluated the effects in reducing spontaneous and cue-induced craving for several substances of abuse. In Table 1, clinical studies investigating the therapeutic potential of TMS are detailed for the major classes of substances of abuse. Starting from preclinical observations that optogenetic stimulation of prefrontal areas could revert the compulsive cocaine-seeking in rats, a pilot open-label clinical study was conducted by our group (Terraneo et al. 2016). Multiple sessions of high-frequency rTMS of the left DLPFC were reported to reduce spontaneous craving for cocaine and increased the abstinence rates, as assessed by the number of cocainefree drug tests (Terraneo et al. 2016). Further pilot clinical studies report that rTMS of the left DLPFC is effective in reducing craving and intake (Politi et al. 2008; Bolloni et al. 2016; Rapinesi et al. 2016). As mentioned earlier, the mechanisms by which rTMS of DLPFC is potentially useful for reducing symptoms related to cocaine addiction are linked to the modulatory effects on neurotransmitter systems (Volkow et al. 2004; Diana et al. 2017). Dopamine signaling is a key candidate to explain the rTMS effects. Neuroimaging studies showed that rTMS of frontal brain regions causes an increase of dopamine levels within basal ganglia (Strafella et al. 2001, 2003) and cortical areas (Cho and Strafella 2009), confirming preclinical findings. These studies showed an increase of dopamine efflux in frontal brain areas, NAc, and hippocampus (Kanno et al. 2003). Although direct stimulation of basal ganglia complex is less likely, as the intensity of the induced magnetic field decays with distance from the coil (Hallett 2000), rTMS can cause secondary activation of subcortical areas anatomically connected (direct or indirect) to the DLPFC (Ilmoniemi et al. 1997; Bestmann et al. 2004; Paus and Barrett 2004). Left DLPFC has been the targeted area for other studies investigating the therapeutic potential of rTMS for SUDs. Open and blinded clinical studies reported that high-frequency rTMS is effective in reducing spontaneous and cue-induced craving in smokers (Johann et al. 2003; Li et al. 2013; Dinur-Klein et al. 2014). Another relevant factor in determining the clinical effects of rTMS is drug consumption. Some studies indicated that active rTMS results in a substantial reduction in number of drinks per day in individuals with alcoholism and in number of cigarettes smoked and level of nicotine addiction in smokers (Eichhammer et al. 2003; Ceccanti et al. 2015; Addolorato et al. 2017). So far, only a few studies have investigated the rTMS effects targeting the right DLPFC. One study reported a reduction in craving following multiple sessions of rTMS (Mishra et al. 2015), whereas no anticraving effects were reported by another study (Herremans et al. 2015). Additionally, bilateral DLPFC stimulation reduced spontaneous craving for alcohol (Kling et al. 1990). In summary, the studies conducted so far suggest that rTMS of the DLPFC can reduce drug-seeking and -taking behaviors but do not provide a clear answer on durability of rTMS efficacy or whether there are better stimulation parameters for rTMS protocols. Further clinical work in larger samples with controlled trial designs is needed to investigate the potential role of rTMS in addiction.

\section{SUMMARY AND FUTURE DIRECTIONS}

The ability to modulate addiction-related behaviors in a circuit-specific manner through noninvasive brain stimulation techniques, such as rTMS, is a powerful alternative for cocaine use, as no FDA-approved pharmacotherapy is available. An increasing number of studies report that rTMS stimulation of the DLPFC is able to reduce craving to several substances of abuse. However, clinical studies investigating the therapeutic potential of rTMS for addictive disorders are still limited by small sample size, design variability, and lack of a sham-controlled group. Other sources of variability across the studies include differences in stimulation parameters, clinical assessment question- 


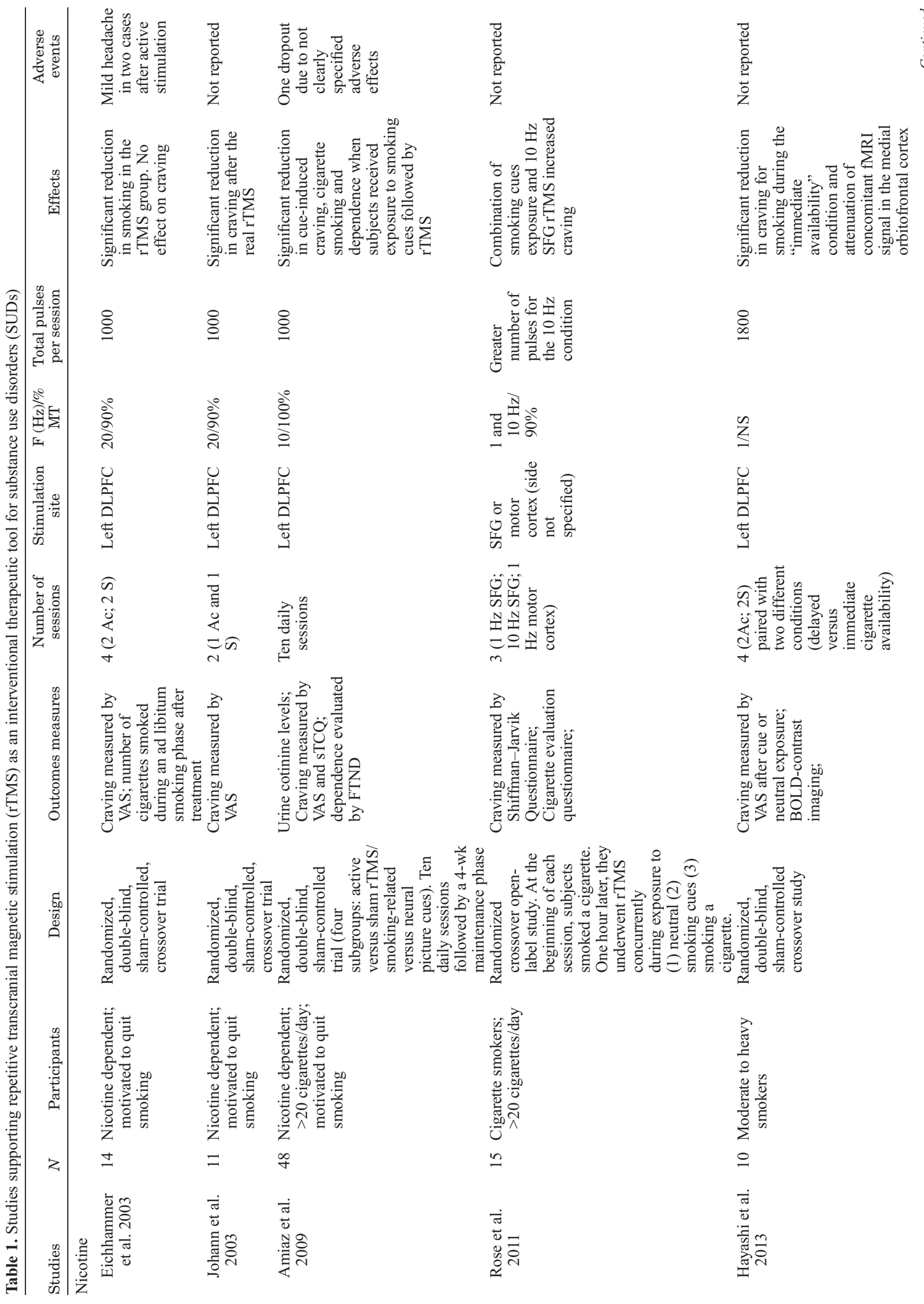




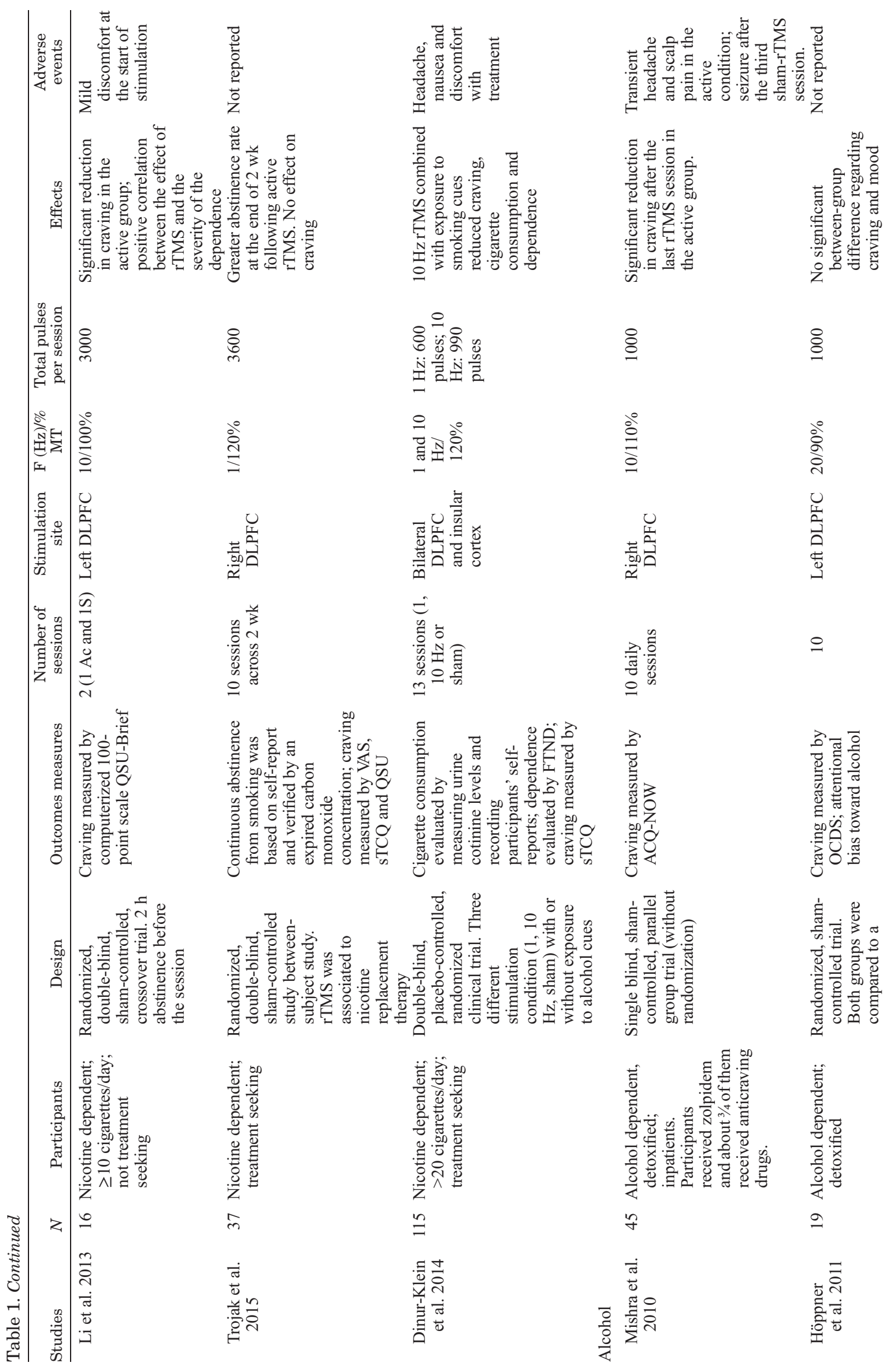



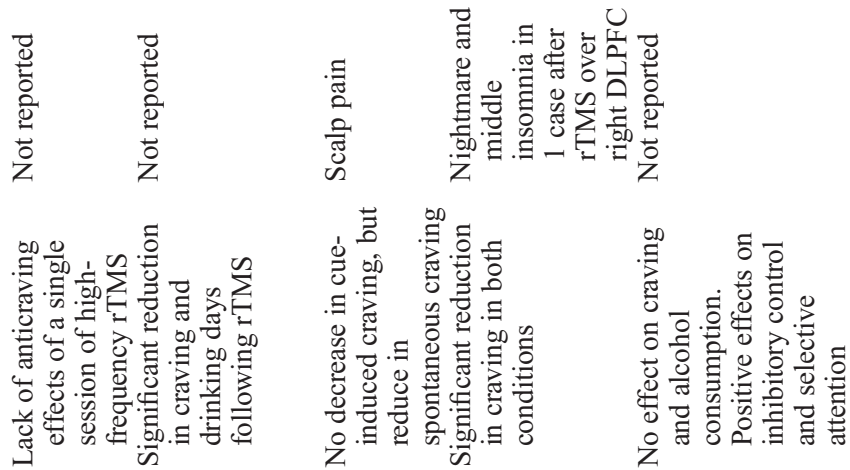

$\stackrel{8}{2} \stackrel{2}{2}$

$\stackrel{8}{\circ} \quad @$

8

응

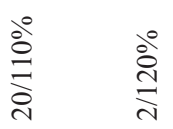

$\begin{array}{ll}\stackrel{\circ}{0} & \stackrel{0}{0} \\ \frac{1}{3} & \frac{1}{3}\end{array}$

$\stackrel{\stackrel{\circ}{0}}{\frac{0}{0}}$

$\stackrel{\stackrel{8}{8}}{\stackrel{1}{0}}$

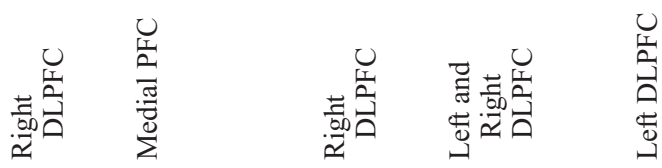

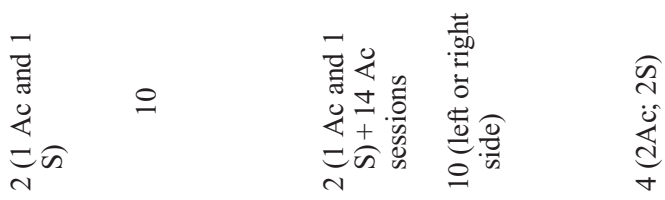

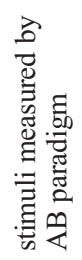
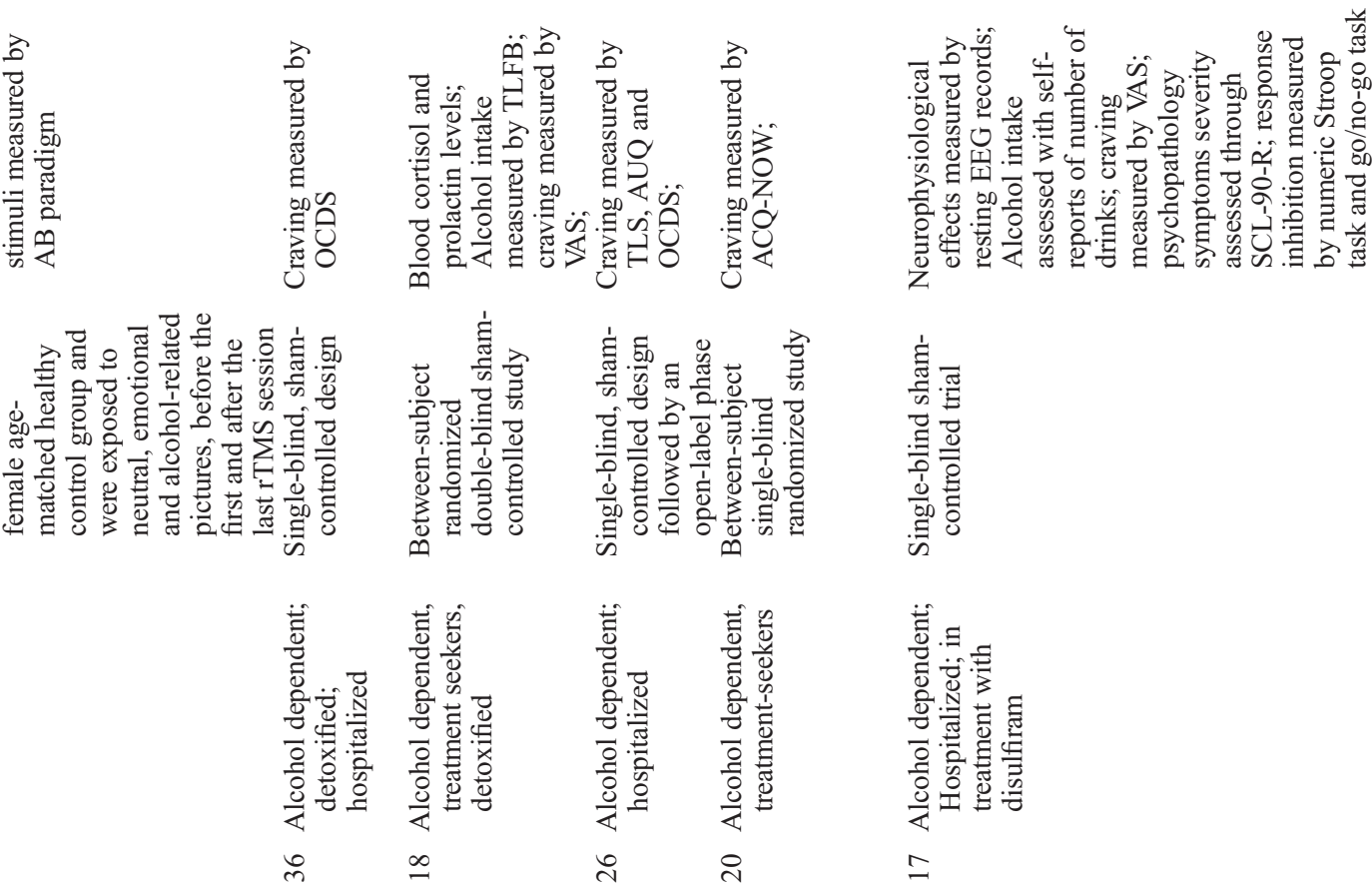

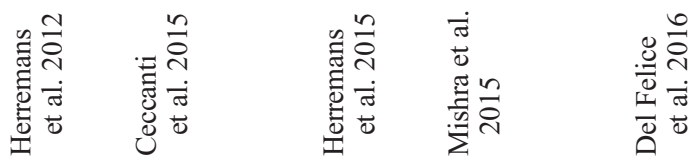









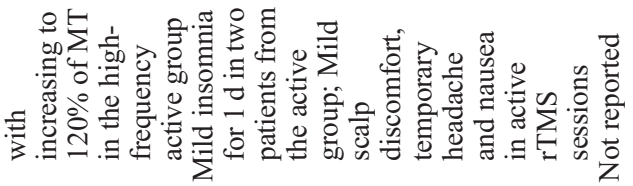

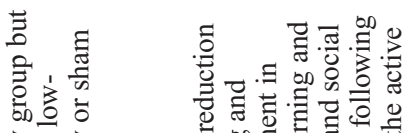

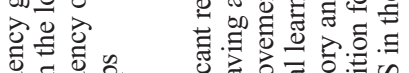

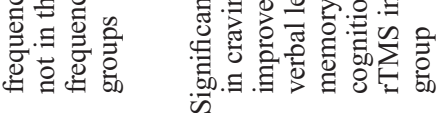

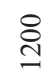

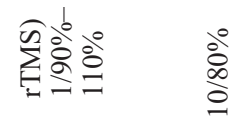

垈

n
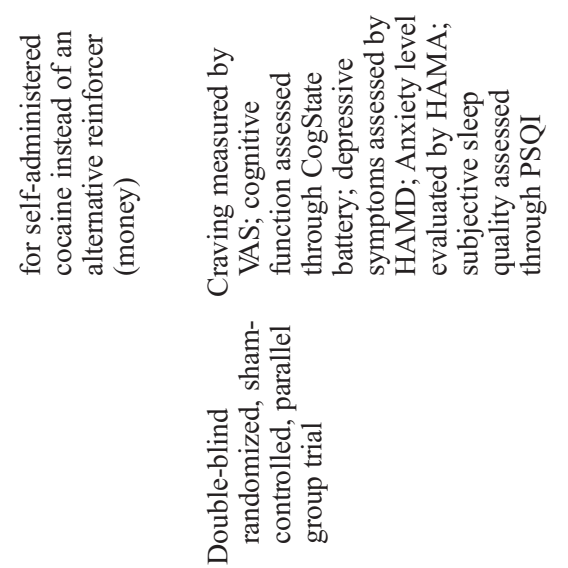

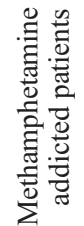

우

홍

离

ن
으

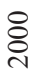

$\stackrel{\circ}{\circ}$

焉

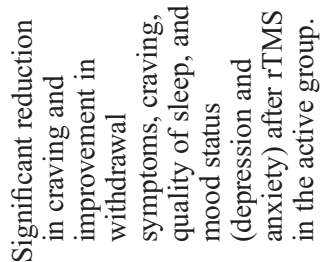

西
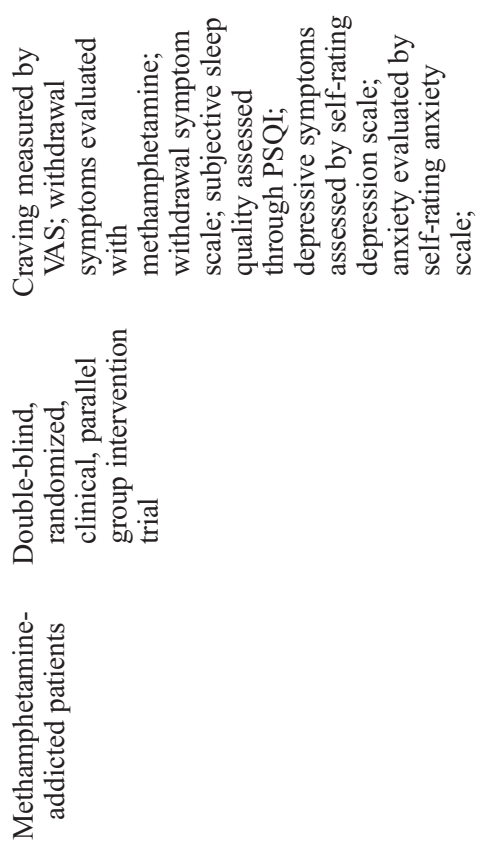

$\stackrel{\infty}{+}$

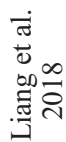

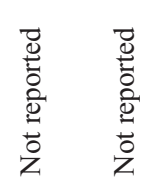

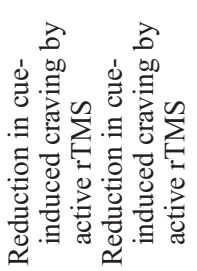

¿

官

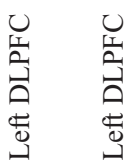

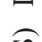

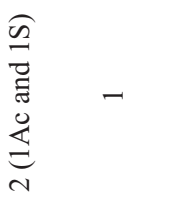

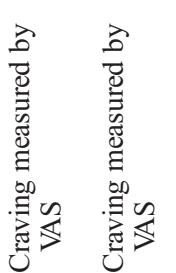
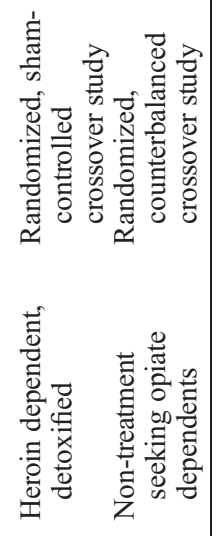

त 2

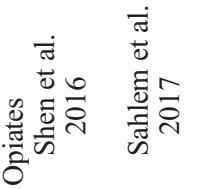

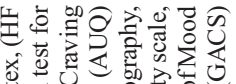
定:

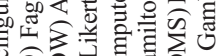

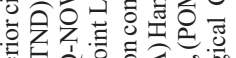

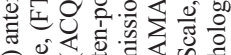
O己 यक口

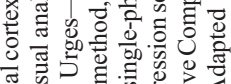

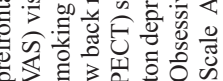

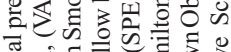

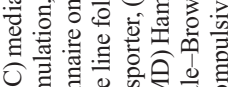
o.

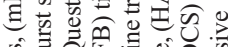

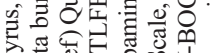
on

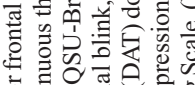

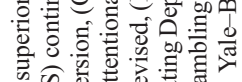

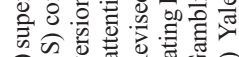

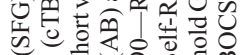

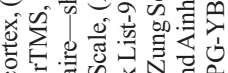

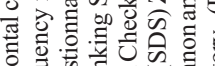

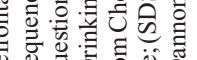

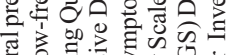

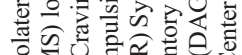

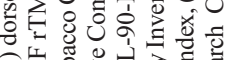

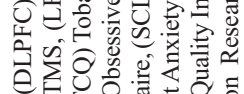

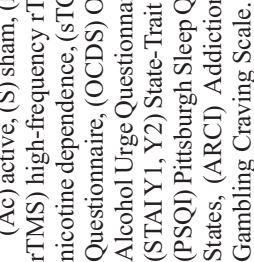


naires, and patient sample features. All together this variability may account for conflicting clinical outcomes. Therefore, double-blind sham-controlled and long-term follow-up studies are necessary to test the efficacy, tolerability, and safety of rTMS in addicted populations. These studies will also allow us to understand how neuromodulatory therapies can be further improved. Developing novel TMS protocols can allow us to achieve stronger and more persistent long-term neuroplasticity changes. Moreover, stimulation of different and deeper brain areas may be pursued with advanced coils (e.g., H-coils) that have less attenuation of the electromagnetic field with depth and thus target other key areas involved in addiction pathophysiology. A better knowledge of mechanisms and factors underlying the aftereffects that TMS induces can potentially allow us to tailor TMS parameters on the individual physiology of the patient. When pursuing rTMS as a potential treatment, one should also consider advances in neuroimaging and neurophysiology investigations in the attempt to biotype addicted individuals and identify biomarkers predicting the treatment response.

\section{REFERENCES}

Addolorato G, Antonelli M, Cocciolillo F, Vassallo GA, Tarli C, Sestito L, Mirijello A, Ferrulli A, Pizzuto DA, Camardese G, et al. 2017. Deep transcranial magnetic stimulation of the dorsolateral prefrontal cortex in alcohol use disorder patients: effects on dopamine transporter availability and alcohol intake. Eur Neuropsychopharmacol 27: 450-461. doi:10.1016/j .euroneuro.2017.03.008

American Psychiatric Association. 2013. Diagnostic and statistical manual of mental disorders: DSM-5. American Psychiatric Association, Arlington, VA.

Amiaz R, Levy D, Vainiger D, Grunhaus L, Zangen A. 2009. Repeated high-frequency transcranial magnetic stimulation over the dorsolateral prefrontal cortex reduces cigarette craving and consumption. Addiction 104: 653-660. doi:10.1111/j .1360-0443.2008.02448.x

Berndt A, Deisseroth K. 2015. Expanding the optogenetics toolkit. Science 349: 590-591. doi:10.1126/science.aac7889

Bestmann S, Baudewig J, Siebner HR, Rothwell JC, Frahm J. 2004. Functional MRI of the immediate impact of transcranial magnetic stimulation on cortical and subcortical motor circuits. Eur J Neurosci 19: 1950-1962. doi:10.1111/j.14609568.2004.03277.x

Blum K, Chen AL, Chen TJ, Braverman ER, Reinking J, Blum SH, Cassel K, Downs BW, Waite RL, Williams L, et al. 2008. Activation instead of blocking mesolimbic dopaminergic reward circuitry is a preferred modality in the long term treatment of reward deficiency syndrome (RDS): a commentary. Theor Biol Med Model 5: 24. doi:10.1186/1742-4682-5-24

Bolloni C, Panella R, Pedetti M, Frascella AG, Gambelunghe C, Piccoli T, Maniaci G, Brancato A, Cannizzaro C, Diana M. 2016. Bilateral transcranial magnetic stimulation of the prefrontal cortex reduces cocaine intake: a pilot study. Front Psychiatry 7: 133. doi:10.3389/fpsyt.2016.00133

Bunce SC, Harris J, Izzetoglu K, Ayaz H, Izzetoglu M, Pourrezaei K, Onaral B. 2013. Functional near-infrared spectroscopy in addiction treatment: Preliminary evidence as a biomarker of treatment response. In Foundations of Augmented Cognition. $A C$ 2013. Lecture Notes in Computer Science (Schmorrow DD, Fidopiastis CM), pp. 250-258. Springer, Berlin

Camprodon JA, Martínez-Raga J, Alonso-Alonso M, Shih M-C, Pascual-Leone A. 2007. One session of high frequency repetitive transcranial magnetic stimulation (rTMS) to the right prefrontal cortex transiently reduces cocaine craving. Drug
Alcohol Depend 86: 91-94. doi:10.1016/j.drugalcdep.2006 .06 .002

Cárdenas-Morales L, Nowak DA, Kammer T, Wolf RC, Schönfeldt-Lecuona C. 2010. Mechanisms and applications of thetaburst rTMS on the human motor cortex. Brain Topogr 22: 294-306. doi:10.1007/s10548-009-0084-7

Ceccanti M, Inghilleri M, Attilia ML, Raccah R, Fiore M, Zangen A, Ceccanti M. 2015. Deep TMS on alcoholics: effects on cortisolemia and dopamine pathway modulation. A pilot study. Can J Physiol Pharmacol 93: 283-290. doi:10.1139/cjpp-2014-0188

Cheeran B, Talelli P, Mori F, Koch G, Suppa A, Edwards M, Houlden H, Bhatia K, Greenwood R, Rothwell JC. 2008. A common polymorphism in the brain-derived neurotrophic factor gene $(B D N F)$ modulates human cortical plasticity and the response to rTMS. J Physiol 586: 5717-5725. doi:10.1113/ jphysiol.2008.159905

Chen BT, Yau HJ, Hatch C, Kusumoto-Yoshida I, Cho SL, Hopf FW, Bonci A. 2013a. Rescuing cocaine-induced prefrontal cortex hypoactivity prevents compulsive cocaine seeking. $\mathrm{Na}$ ture 496: 359-362. doi:10.1038/nature 12024

Chen J, Tan Z, Zeng L, Zhang X, He Y, Gao W, Wu X, Li Y, Bu B, Wang W, et al. 2013b. Heterosynaptic long-term depression mediated by ATP released from astrocytes. Glia 61: 178-191. doi:10.1002/glia.22425

Chervyakov AV, Chernyavsky AY, Sinitsyn DO, Piradov MA. 2015. Possible mechanisms underlying the therapeutic effects of transcranial magnetic stimulation. Front Hum Neurosci 9: 303. doi:10.3389/fnhum.2015.00303

Cho SS, Strafella AP. 2009. rTMS of the left dorsolateral prefrontal cortex modulates dopamine release in the ipsilateral anterior cingulate cortex and orbitofrontal cortex. PLoS One 4: e6725. doi:10.1371/journal.pone.0006725

Cirillo G, Di Pino G, Capone F, Ranieri F, Florio L, Todisco V, Tedeschi G, Funke K, Di Lazzaro V. 2017. Neurobiological after-effects of non-invasive brain stimulation. Brain Stimul 10: 1 -18. doi:10.1016/j.brs.2016.11.009

Cohen H, Kaplan Z, Kotler M, Kouperman I, Moisa R, Grisaru N. 2004. Repetitive transcranial magnetic stimulation of the right dorsolateral prefrontal cortex in posttraumatic stress disorder: a double-blind, placebo-controlled study. Am J Psychiatry 161: 515-524. doi:10.1176/appi.ajp.161.3.515

Del Felice A, Bellamoli E, Formaggio E, Manganotti P, Masiero S, Cuoghi G, Rimondo C, Genetti B, Sperotto M, Corso F, et al. 2016. Neurophysiological, psychological and behavioural correlates of rTMS treatment in alcohol dependence. Drug Alcohol Depend 158: 147-153.

Di Lazzaro V, Profice P, Ranieri F, Capone F, Dileone M, Oliviero A, Pilato F. 2012. I-wave origin and modulation. Brain Stimul 5: 512-525. doi:10.1016/j.brs.2011.07.008

Diana M, Raij T, Melis M, Nummenmaa A, Leggio L, Bonci A. 2017. Rehabilitating the addicted brain with transcranial magnetic stimulation. Nat Rev Neurosci 18: 685-693. doi:10.1038/ nrn.2017.113

Dinur-Klein L, Dannon P, Hadar A, Rosenberg O, Roth Y, Kotler M, Zangen A. 2014. Smoking cessation induced by deep repetitive transcranial magnetic stimulation of the prefrontal and insular cortices: a prospective, randomized controlled trial. Biol Psychiatry 76: 742-749. doi:10.1016/j.biopsych.2014.05.020

Doeltgen SH, Ridding MC. 2011. Modulation of cortical motor networks following primed theta burst transcranial magnetic stimulation. Exp Brain Res 215: 199-206. doi:10.1007/s00221011-2886-6

Edgley SA, Eyre JA, Lemon RN, Miller S. 1997. Comparison of activation of corticospinal neurons and spinal motor neurons by magnetic and electrical transcranial stimulation in the lumbosacral cord of the anaesthetized monkey. Brain 120: 839853. doi:10.1093/brain/120.5.839

Eichhammer P, Langguth B, Marienhagen J, Kleinjung T, Hajak G. 2003. Neuronavigated repetitive transcranial magnetic stimulation in patients with tinnitus: a short case series. Biol Psychiatry 54: 862-865. doi:10.1016/S0006-3223(02)01896-6

Etiévant A, Manta S, Latapy C, Magno LAV, Fecteau S, Beaulieu J-M. 2015. Repetitive transcranial magnetic stimulation induc- 
es long-lasting changes in protein expression and histone acetylation. Sci Rep 5: 16873. doi: 10.1038/srep 16873

Everitt BJ, Robbins TW. 2005. Neural systems of reinforcement for drug addiction: from actions to habits to compulsion. Nat Neurosci 8: 1481-1489. doi:10.1038/nn1579

Feil J, Zangen A. 2010. Brain stimulation in the study and treatment of addiction. Neurosci Biobehav Rev 34: 559-574. doi:10.1016/j.neubiorev.2009.11.006

Feltenstein MW, See RE. 2009. The neurocircuitry of addiction: an overview. Br J Pharmacol 154: 261-274. doi:10.1038/bjp .2008 .51

Gamboa OL, Antal A, Moliadze V, Paulus W. 2010. Simply longer is not better: reversal of theta burst after-effect with prolonged stimulation. Exp Brain Res 204: 181-187. doi:10 .1007/s00221-010-2293-4

George O, Koob GF. 2010. Individual differences in prefrontal cortex function and the transition from drug use to drug dependence. Neurosci Biobehav Rev 35: 232-247. doi:10.1016/j neubiorev.2010.05.002

Goldstein RZ, Volkow ND. 2002. Drug addiction and its underlying neurobiological basis: neuroimaging evidence for the involvement of the frontal cortex. Am J Psychiatry 159: 1642-1652. doi:10.1176/appi.ajp.159.10.1642

Goldstein RZ, Volkow ND. 2011. Dysfunction of the prefrontal cortex in addiction: neuroimaging findings and clinical implications. Nat Rev Neurosci 12: 652-669. doi:10.1038/nrn3119

Hadley D, Anderson BS, Borckardt JJ, Arana A, Li X, Nahas Z, George MS. 2011. Safety, tolerability, and effectiveness of high doses of adjunctive daily left prefrontal repetitive transcranial magnetic stimulation for treatment-resistant depression in a clinical setting. $J$ ECT 27: 18-25. doi:10.1097/YCT $.0 \mathrm{~b} 013 \mathrm{e} 3181 \mathrm{ce} 1 \mathrm{a} 8 \mathrm{c}$

Hallett M. 2000. Transcranial magnetic stimulation and the human brain. Nature 406: 147-150. doi:10.1038/35018000

Hanlon CA, Dowdle LT, Austelle CW, Devries W, Mithoefer O, Badran BW, George MS. 2015. What goes up, can come down: novel brain stimulation paradigms may attenuate craving and craving-related neural circuitry in substance dependent individuals. Brain Res 1628: 199-209. doi:10.1016/j.brainres .2015 .02 .053

Hayashi T, Ko JH, Strafella AP, Dagher A. 2013. Dorsolateral prefrontal and orbitofrontal cortex interactions during selfcontrol of cigarette craving. Proc Natl Acad Sci 110: 44224427.

Herremans SC, Baeken C, Vanderbruggen N, Vanderhasselt M-A, Zeeuws D, Santermans L, De Raedt R. 2012. No influence of one right-sided prefrontal HF-rTMS session on alcohol craving in recently detoxified alcohol-dependent patients: results of a naturalistic study. Drug Alcohol Depend 120: 209213.

Herremans SC, Van Schuerbeek P, De Raedt R, Matthys F, Buyl R, De Mey J, Baeken C. 2015. The impact of accelerated right prefrontal high-frequency repetitive transcranial magnetic stimulation (rTMS) on cue-reactivity: an FMRI study on craving in recently detoxified alcohol-dependent patients. PLoS One 10: e0136182. doi:10.1371/journal.pone.0136182

Hong LE, Gu H, Yang Y, Ross TJ, Salmeron BJ, Buchholz B, Thaker GK, Stein EA. 2009. Association of nicotine addiction and nicotine's actions with separate cingulate cortex functional circuits. Arch Gen Psychiatry 66: 431-441. doi:10.1001/arch genpsychiatry.2009.2

Höppner J, Broese T, Wendler L, Berger C, Thome J. 2011. Repetitive transcranial magnetic stimulation (rTMS) for treatment of alcohol dependence. World J Biol Psychiatry 12: 5762 .

Huang YZ, Edwards MJ, Rounis E, Bhatia KP, Rothwell JC. 2005. Theta burst stimulation of the human motor cortex. Neuron 45: 201-206. doi:10.1016/j.neuron.2004.12.033

Ilmoniemi RJ, Kičić D. 2010. Methodology for combined TMS and EEG. Brain Topogr 22: 233-248. doi:10.1007/s10548009-0123-4

Ilmoniemi RJ, Virtanen J, Ruohonen J, Karhu J, Aronen HJ, Näätänen R, Katila T. 1997. Neuronal responses to magnetic stim- ulation reveal cortical reactivity and connectivity. Neuroreport 8: 3537-3540. doi:10.1097/00001756-199711100-00024

Ilmoniemi RJ, Ruohonen J, Karhu J. 1999. Transcranial magnetic stimulation - a new tool for functional imaging of the brain. Crit Rev Biomed Eng 27: 241-284.

Jackson MP, Rahman A, Lafon B, Kronberg G, Ling D, Parra LC, Bikson M. 2016. Animal models of transcranial direct current stimulation: methods and mechanisms. Clin Neurophysiol 127: 3425-3454. doi:10.1016/j.clinph.2016.08.016

Johann M, Wiegand R, Kharraz A, Bobbe G, Sommer G, Hajak G, Wodarz N, Eichhammer P. 2003. [Transcranial magnetic stimulation for nicotine dependence]. Psychiatr Prax 30: S129-S131. doi:10.1055/s-2003-39733

Jovanovski D, Erb S, Zakzanis KK. 2005. Neurocognitive deficits in cocaine users: a quantitative review of the evidence. $J$ Clin Exp Neuropsychol 27: 189-204. doi:10.1080/ 13803390490515694

Kalivas PW, O'Brien C. 2008. Drug addiction as a pathology of staged neuroplasticity. Neuropsychopharmacology 33: 166180. doi:10.1038/sj.npp.1301564

Kanno M, Matsumoto M, Togashi H, Yoshioka M, Mano Y 2003. Effects of repetitive transcranial magnetic stimulation on behavioral and neurochemical changes in rats during an elevated plus-maze test. J Neurol Sci 211: 5-14. doi:10 .1016/S0022-510X(03)00030-3

Karabanov A, Ziemann U, Hamada M, George MS, Quartarone A, Classen J, Massimini M, Rothwell J, Siebner HR. 2015. Consensus paper: probing homeostatic plasticity of human cortex with non-invasive transcranial brain stimulation. Brain Stimul 8: 993-1006. doi:10.1016/j.brs.2015.06.017

Kenny PJ, Hoyer D, Koob GF. 2018. Animal models of addiction and neuropsychiatric disorders and their role in drug discovery: honoring the legacy of Athina Markou. Biol Psychiatry 83: 940-946. doi:10.1016/j.biopsych.2018.02.009

Kling JW, Yarita M, Yamamoto T, Matsumiya Y. 1990. Memory for conditioned taste aversions is diminished by transcranial magnetic stimulation. Physiol Behav 48: 713-717. doi:10 .1016/0031-9384(90)90216-Q

Koob GF, Volkow ND. 2010. Neurocircuitry of addiction. Neuropsychopharmacology 35: 217-238. doi:10.1038/npp.2009 .110

Labruna L, Jamil A, Fresnoza S, Batsikadze G, Kuo M-F, Vanderschelden B, Ivry RB, Nitsche MA. 2016. Efficacy of anodal transcranial direct current stimulation is related to sensitivity to transcranial magnetic stimulation. Brain Stimul 9: 8-15. doi:10.1016/j.brs.2015.08.014

Lanza G, Cantone M, Lanuzza B, Pennisi M, Bella R, Pennisi G, Ferri R. 2015. Distinctive patterns of cortical excitability to transcranial magnetic stimulation in obstructive sleep apnea syndrome, restless legs syndrome, insomnia, and sleep deprivation. Sleep Med Rev 19: 39-50. doi:10.1016/j.smrv.2014.04.001

Lenz M, Platschek S, Priesemann V, Becker D, Willems LM, Ziemann U, Deller T, Müller-Dahlhaus F, Jedlicka P, Vlachos A. 2015. Repetitive magnetic stimulation induces plasticity of excitatory postsynapses on proximal dendrites of cultured mouse CA1 pyramidal neurons. Brain Struct Funct 220: 3323-3337. doi:10.1007/s00429-014-0859-9

Levy D, Shabat-Simon M, Shalev U, Barnea-Ygael N, Cooper A, Zangen A. 2007. Repeated electrical stimulation of rewardrelated brain regions affects cocaine but not "natural" reinforcement. J Neurosci 27: 14179-14189. doi:10.1523/JNEUR OSCI.4477-07.2007

Li X, Hartwell KJ, Owens M, Lematty T, Borckardt JJ, Hanlon CA, Brady KT, George MS. 2013. Repetitive transcranial magnetic stimulation of the dorsolateral prefrontal cortex reduces nicotine cue craving. Biol Psychiatry 73: 714-720. doi:10 $.1016 /$ j.biopsych.2013.01.003

Liang Y, Wang L, Yuan T-FF. 2018. Targeting withdrawal symptoms in men addicted to methamphetamine with transcranial magnetic stimulation: a randomized clinical trial. JAMA Psychiatry 75: 1199-1201.

Martinez D, Urban N, Grassetti A, Chang D, Hu M-C, Zangen A, Levin FR, Foltin R, Nunes EV. 2018. Transcranial magnetic 
stimulation of medial prefrontal and cingulate cortices reduces cocaine self-administration: a pilot study. Front Psychiatry 9: 80 .

McHugh MJ, Demers CH, Braud J, Briggs R, Adinoff B, Stein EA. 2013. Striatal-insula circuits in cocaine addiction: implications for impulsivity and relapse risk. Am J Drug Alcohol Abuse 39: 424-432. doi:10.3109/00952990.2013.847446

Mishra BR, Nizamie SH, Das B, Praharaj SK. 2010. Efficacy of repetitive transcranial magnetic stimulation in alcohol dependence: a sham-controlled study. Addiction 105: 49-55.

Mishra BR, Praharaj SK, Katshu MZUH, Sarkar S, Nizamie SH. 2015. Comparison of anticraving efficacy of right and left repetitive transcranial magnetic stimulation in alcohol dependence: a randomized double-blind study. J Neuropsychiatr Clin Neurosci 27: e54-e59. doi:10.1176/appi.neuropsych .13010013

Modirrousta M, Meek BP, Wikstrom SL. 2018. Efficacy of twicedaily vs once-daily sessions of repetitive transcranial magnetic stimulation in the treatment of major depressive disorder: a retrospective study. Neuropsychiatr Dis Treat 14: 309-316. doi:10.2147/NDT.S151841

Nestler E. 2005. The neurobiology of cocaine addiction. Sci Pract Perspect 3: 4-10. doi:10.1151/spp05314

Pascual-Leone A, Valls-Solé J, Wassermann EM, Hallett M. 1994. Responses to rapid-rate transcranial magnetic stimulation of the human motor cortex. Brain 117: 847-858. doi:10 $.1093 / \mathrm{brain} / 117.4 .847$

Paus T, Barrett J. 2004. Transcranial magnetic stimulation (TMS) of the human frontal cortex: implications for repetitive TMS treatment of depression. J Psychiatry Neurosci 29: 268-279.

Pell GS, Roth Y, Zangen A. 2011. Modulation of cortical excitability induced by repetitive transcranial magnetic stimulation: influence of timing and geometrical parameters and underlying mechanisms. Prog Neurobiol 93: 59-98. doi:10.1016/j .pneurobio.2010.10.003

Politi E, Fauci E, Santoro A, Smeraldi E. 2008. Daily sessions of transcranial magnetic stimulation to the left prefrontal cortex gradually reduce cocaine craving. Am J Addict 17: 345-346. doi:10.1080/10550490802139283

Rapinesi C, Del Casale A, Di Pietro S, Ferri VR, Piacentino D, Sani G, Raccah RN, Zangen A, Ferracuti S, Vento AE, et al. 2016. Add-on high frequency deep transcranial magnetic stimulation (dTMS) to bilateral prefrontal cortex reduces cocaine craving in patients with cocaine use disorder. Neurosci Lett 629: 43-47. doi:10.1016/j.neulet.2016.06.049

Rose JE, McClernon FJ, Froeliger B, Behm FM, Preud'homme X, Krystal AD. 2011. Repetitive transcranial magnetic stimulation of the superior frontal gyrus modulates craving for cigarettes. Biol Psychiatry 70: 794-799.

Rossi S, Hallett M, Rossini PM, Pascual-Leone A, The Safety of TMS Consensus Group. 2012. Safety, ethical considerations, and application guidelines for the use of transcranial magnetic stimulation in clinical practice and research. Clin Neurophysiol 120: 323-330. doi:10.1016/j.clinph.2009.08.016

Sahlem GL, Baker NL, George MS, Malcolm RJ, McRae-Clark AL. 2018. Repetitive transcranial magnetic stimulation (rTMS) administration to heavy cannabis users. Am J Drug Alcohol Abuse 44: 47-55.

Salvador R, Silva S, Basser PJ, Miranda PC. 2011. Determining which mechanisms lead to activation in the motor cortex: a modeling study of transcranial magnetic stimulation using realistic stimulus waveforms and sulcal geometry. Clin Neurophysiol 122: 748-758. doi:10.1016/j.clinph.2010.09.022

Schulze L, Feffer K, Lozano C, Giacobbe P, Daskalakis ZJ, Blumberger DM, Downar J. 2018. Number of pulses or number of sessions? An open-label study of trajectories of improvement for once- vs. twice-daily dorsomedial prefrontal rTMS in major depression. Brain Stimul 11: 327-336. doi:10.1016/j.brs.2017.11.002

Shen Y, Cao X, Tan T, Shan C, Wang Y, Pan J, He H, Yuan TF. 2016. 10-Hz repetitive transcranial magnetic stimulation of the left dorsolateral prefrontal cortex reduces heroin cue craving in long-term addicts. Bioll Psychiatry 80: e13-e14.
Siebner HR, Bergmann TO, Bestmann S, Massimini M, Johansen-Berg H, Mochizuki H, Bohning DE, Boorman ED, Groppa S, Miniussi C, et al. 2009. Consensus paper: combining transcranial stimulation with neuroimaging. Brain Stimul 2: 58-80. doi:10.1016/j.brs.2008.11.002

Silva S, Basser PJ, Miranda PC. 2008. Elucidating the mechanisms and loci of neuronal excitation by transcranial magnetic stimulation using a finite element model of a cortical sulcus. Clin Neurophysiol 119: 2405-2413. doi:10.1016/j.clinph .2008.07.248

Silvanto J, Cattaneo Z, Battelli L, Pascual-Leone A. 2008. Baseline cortical excitability determines whether TMS disrupts or facilitates behavior. J Neurophysiol 99: 2725-2730. doi:10 $.1152 /$ jn.01392.2007

Sinha R. 2011. New findings on biological factors predicting addiction relapse vulnerability. Curr Psychiatry Rep 13: 398-405. doi:10.1007/s11920-011-0224-0

Stefanik MT, Moussawi K, Kupchik YM, Smith KC, Miller RL, Huff ML, Deisseroth K, Kalivas PW, Lalumiere RT. 2013. Optogenetic inhibition of cocaine seeking in rats. Addict Biol 18: 50-53. doi:10.1111/j.1369-1600.2012.00479.x

Strafella AP, Paus T, Barrett J, Dagher A. 2001. Repetitive transcranial magnetic stimulation of the human prefrontal cortex induces dopamine release in the caudate nucleus. $J$ Neurosci 21: 1-4. doi:10.1523/JNEUROSCI.21-15-j0003.2001

Strafella AP, Paus T, Fraraccio M, Dagher A. 2003. Striatal dopamine release induced by repetitive transcranial magnetic stimulation of the human motor cortex. Brain 126: 26092615. doi:10.1093/brain/awg268

Su H, Zhong N, Gan H, Wang J, Han H, Chen T, Li X, Ruan X, Zhu Y, Jiang H, et al. 2017. High frequency repetitive transcranial magnetic stimulation of the left dorsolateral prefrontal cortex for methamphetamine use disorders: a randomised clinical trial. Drug Alcohol Depend 175: 84-91.

Terraneo A, Leggio L, Saladini M, Ermani M, Bonci A, Gallimberti L. 2016. Transcranial magnetic stimulation of dorsolateral prefrontal cortex reduces cocaine use: a pilot study. Eur Neuropsychopharmacol 26: 37-44. doi:10.1016/j.euroneuro .2015.11.011

Tigaret CM, Olivo V, Sadowski JHLP, Ashby MC, Mellor JR. 2016. Coordinated activation of distinct $\mathrm{Ca}^{2+}$ sources and metabotropic glutamate receptors encodes Hebbian synaptic plasticity. Nat Commun 7: 10289. doi:10.1038/ncomms10289

Trojak B, Meille V, Achab S, Lalanne L, Poquet H, Ponavoy E, Blaise E, Bonin B, Chauvet-Gelinier J-C. 2015. Transcranial magnetic stimulation combined with nicotine replacement therapy for smoking cessation: a randomized controlled trial. Brain Stimulation 8: 1168-1174.

Vlachos A, Muller-Dahlhaus F, Rosskopp J, Lenz M, Ziemann U, Deller T. 2012. Repetitive magnetic stimulation induces functional and structural plasticity of excitatory postsynapses in mouse organotypic hippocampal slice cultures. J Neurosci 32: 17514-17523. doi:10.1523/JNEUROSCI.0409-12.2012

Volkow ND, Wang GJ, Fowler JS, Gatley SJ, Ding YS, Logan J, Dewey SL, Hitzemann R, Lieberman J. 1996. Relationship between psychostimulant-induced "high" and dopamine transporter occupancy. Proc Natl Acad Sci 93: 10388-10392. doi:10.1073/pnas.93.19.10388

Volkow ND, Fowler JS, Wang GJ. 2003. The addicted human brain: insights from imaging studies. J Clin Invest 111: 14441451. doi:10.1172/JCI18533

Volkow ND, Fowler JS, Wang G-J. 2004. The addicted human brain viewed in the light of imaging studies: brain circuits and treatment strategies. Neuropharmacology 47: 3-13. doi:10 .1016/j.neuropharm.2004.07.019

Volkow ND, Koob GF, McLellan AT. 2016. Neurobiologic advances from the brain disease model of addiction. $N$ Engl $J$ Med 374: 363-371. doi:10.1056/NEJMra1511480

Zhang X, Mei Y, Liu C, Yu S. 2007. Effect of transcranial magnetic stimulation on the expression of c-Fos and brain-derived neurotrophic factor of the cerebral cortex in rats with cerebral infarct. J Huazhong Univ Sci Technol 27: 415-418. doi:10 .1007/s11596-007-0416-3 


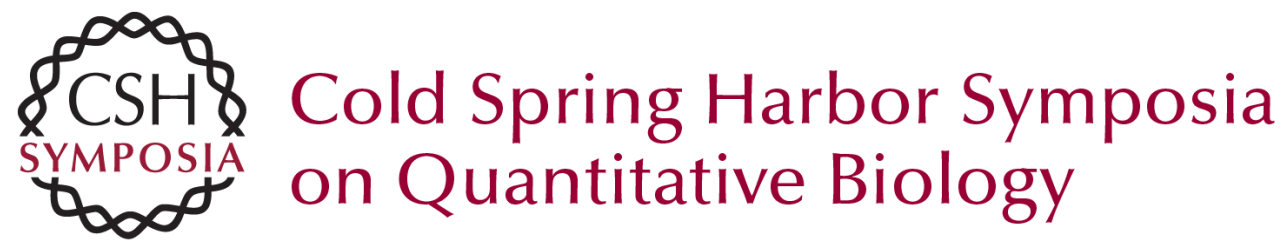

\section{Rewiring the Addicted Brain: Circuits-Based Treatment for Addiction}

Graziella Madeo and Antonello Bonci

Cold Spring Harb Symp Quant Biol 2018 83: 173-184 originally published online May 16, 2019 Access the most recent version at doi:10.1101/sqb.2018.83.038158

References This article cites 92 articles, 6 of which can be accessed free at: http://symposium.cshlp.org/content/83/173.full.html\#ref-list-1

Creative This article is distributed under the terms of the

Commons http://creativecommons.org/licenses/by/4.0/, which permits unrestricted

License reuse and redistribution provided that the original author and source are credited.

Email Alerting Receive free email alerts when new articles cite this article - sign up in Service the box at the top right corner of the article or click here. 